\title{
Differential expression of two types of sucrose synthase-encoding genes in wheat in response to an- aerobiosis, cold shock and light
}

(Endosperm cDNA clones; specific probes; cereals; gene expression; plant gene regulation; stress response)

\author{
Carmen Maraña , Francisco Garcia-Olmedo and Pilar Carbonero \\ Catedra de Bioquimica y Biologia Molecular, Escuela Técnica Superior de Ingenieros Agrónomos, Ciudad Universitaria, 28040 Madrid (Spain)
}

\section{SUMMARY}

The expression of two types of sucrose synthase-encoding genes, $S s 1$ and $S s 2$, in hexaploid wheat (Triticum aestivum, L.), has been investigated using type-specific probes, corresponding to the 250-270 bp C-terminal portions of the respective cDNA clones. Both types of genes are highly expressed in developing endosperm, where the expression of the $S s 2$ type slightly precedes in time that of the $S s 1$ type. Expression of $S s$ genes is lower in etiolated leaves and in roots than in endosperm. In the first two tissues, the $S s I$ mRNA is much more abundant than the $S s 2$ mRNA, and the $S s I$ mRNA level sharply increases in response to anaerobiosis and to cold shock $\left(6^{\circ} \mathrm{C}\right)$, while the level of Ss2 mRNA is not significantly affected. Upon illumination of etiolated leaves, the $S s 1$ level mRNA decreases significantly and the $S s 2 \mathrm{mRNA}$ level increases.

\section{INTRODUCTION}

The enzyme sucrose synthase (Ssase; EC 2.4.1.13.), which catalyzes the reversible reaction UDP + sucrose $\rightleftharpoons$ UDP-glucose + D-fructose, was first characterized in wheat germ by Leloir and coworkers, who also detected its activity in a great variety of plant species and tissues (Cardini et al., 1955). Recent advances on the subject have focused, to some degree, on the maize enzyme, which is a tetramer composed of subunits of $92 \mathrm{kDa}(\mathrm{Su}$

Correspondence to: Dr. P. Carbonero, Bioquimica y Biologia Molecular, Escuela Técnica Superior de Ingenieros Agrónomos, Ciudad Universitaria, 28040 Madrid (Spain) Tel. (1)2444807; Fax 34-1-2434879.

* Present address: Laboratorium voor Genetische Virologie, Vrije Universiteit Brussel, B-1640 (Belgium).

Abbreviations: bp, base pair(s); dap, days after pollination; $1 \times$ Denhardt's, $0.02 \%$ bovine serum albumin $/ 0.02 \%$ Ficoll $/ 0.02 \%$ polyvinylpyrrolidone; kb, kilobase(s) or $1000 \mathrm{bp}$; $\mathrm{nt}$, nucleotide(s); Ssase, sucrose synthase; $S s$, gene encoding $S$ sase; SSC, $0.15 \mathrm{M} \mathrm{NaCl} / 0.015 \mathrm{M}$ $\mathrm{Na}_{3}$ - citrate $\mathrm{pH} 7.6 ; \mathrm{SSPE}, 180 \mathrm{mM} \mathrm{NaCl} / 10 \mathrm{mM} \mathrm{NaH}_{2} \mathrm{PO}_{4} / 1 \mathrm{mM}$ EDTA pH 7.4 ; IRNA, transfer RNA. and Preiss, 1978; Chourey, 1981; Werr et al., 1985). Two non-allelic variants of the enzyme have been characterized (Chourey, 1981; Echt and Chourey, 1985) and the corresponding genes $[S h$ and $S u s(=S s 2=C s s)]$ have been identified, cloned and sequenced (Chourey and Nelson, 1976; Burr and Burr, 1981; Werr et al., 1985; McCarty et al., 1986; Springer et al., 1986).

In wheat, $S$ sase has been partially purified from germ and leaves (Cardini et al., 1955; Larsen et al., 1985), and its physiological role during grain filling (Chevallier and Lingle, 1983; Dale and Housley, 1986) and during cold shock (Calderon and Pontis, 1985) has been investigated. We have recently described two types of $S s$ genes, $S s I$ and $S s 2$, which are linked in the short arms of group-7 chromosomes of hexaploid wheat and other gramineae, and their equivalence to the $S h$ and $S u s$ maize genes, respectively, has been proposed on the basis of the nt sequences of the corresponding cloned cDNAs (Maraña et al., 1988a,b). We have now investigated the differential expression of the two types of genes in response to anaerobiosis, cold shock and light, using type-specific cDNA probes. 
A

SELECTIVE PROBES

SS1 ' 3 '-END OF INSERT IN CLONE PSTB'

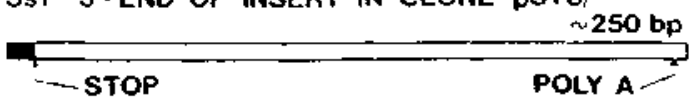

SS2 [3-END OF INSERT IN CLONE pST3;

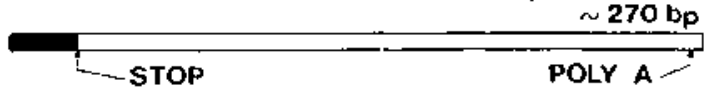

8

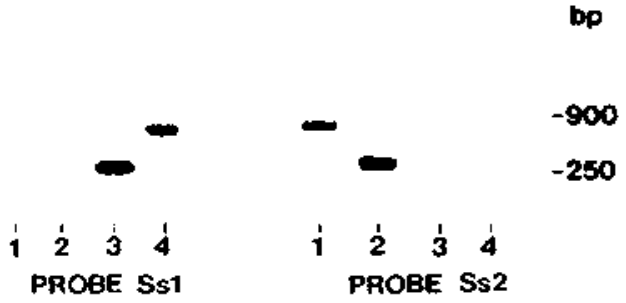

Fig. I. Seiective probes for wheal sucrose synthase $S s /$ and $S s 2$ genes. (Panel A) The type-specific probes were obtained from the inserts in cDNA clones pST8 and pST3 (Marata et al., 1988a), by subcloning their $3^{\prime}$ ends. A Sacl fragment from the insert in clone pST 8 was subcloned in the Sacl site of vector pUC12. A BgIII fragment from clone $\mathrm{pST} 3$ was treated with BAL31 and the Klenow fragment of DNA polymerase l, and then subcioned in the $S \mathrm{mal}$ site of vector pUC12. Black stretches represent 12 bp and 48 bp of the coding regions, respectively. (Panel B) Southern blot hybridization with the type-specific probes of the following DNAs: (1) complete insert from pST3; (2) type-specific Ss2 probe; (3) type-specific SsI probe; (4) complete insert from pST8. The inserts were subjected to electrophoresis in $1.5 \%$ agarose gets.

sion of the two types of genes because their messengers were also of the same size (Maraña et al., 1988a). For these reasons, new probes were obtained for $S s 1$ and $S_{s} 2$ genes that were about 250 bp and 270 bp in length, respectively, and which essentially corresponded to the noncoding 3 '-end regions of the cDNAs. Due to the considerable sequence divergence of these regions (Table I), no reciprocal hybridization between the probes was observed (Fig. 1). However, each of the probes was able to hybridize to the genes of its type in all three chromosomes of group 7 , as was ascertained by Southern blotting (nol shown).

\section{(b) Differential expression of $S s \boldsymbol{I}$ and $S s 2$ genes in different tissues}

The two types of $S s$ genes were essentially expressed during the cell-proliferation phase of endosperm development, but the expression of the $S s /$ type lagged behind that of the $S s 2$ type (Fig. 2A). The specific activities and amounts of the probes used in the dot-blot experiments were practically the same, so the densitometric values represented in Fig. 2A could be considered to reflect the relative abundance of the two types of mRNA at the different times of endosperm development. To make a direct comparison, 
TABLE I

Comparison of nt sequence homologies for wheat and maize sucrose-synthase genes expressed as ${ }^{\circ}$ of identical positions ${ }^{\circ}$

\begin{tabular}{|c|c|c|c|c|c|c|}
\hline \multirow[t]{2}{*}{ Genes } & \multicolumn{2}{|c|}{ Wheal $S s ?$} & \multicolumn{2}{|c|}{ Maize $S h$} & \multicolumn{2}{|c|}{ Maize Sus } \\
\hline & Coding & Noncoding & Coding & Noncoding & Coding & Noncoding \\
\hline Wheat $S s l$ & 79 & 40 & 84 & 52 & 76 & 44 \\
\hline Wheat $S_{52}$ & & & 76 & 47 & 82 & 39 \\
\hline Maize $S h$ & & . & & & 79 & 40 \\
\hline
\end{tabular}

- Comparisons as in Maraña et al. (1988a). Maize Sus sequence from L.C. Hannah (personal commenication). Coding regions compared correspond to about 900 bp of the $C$ terminal. Noncoding regions are untranslated $3^{\prime}$ ends.
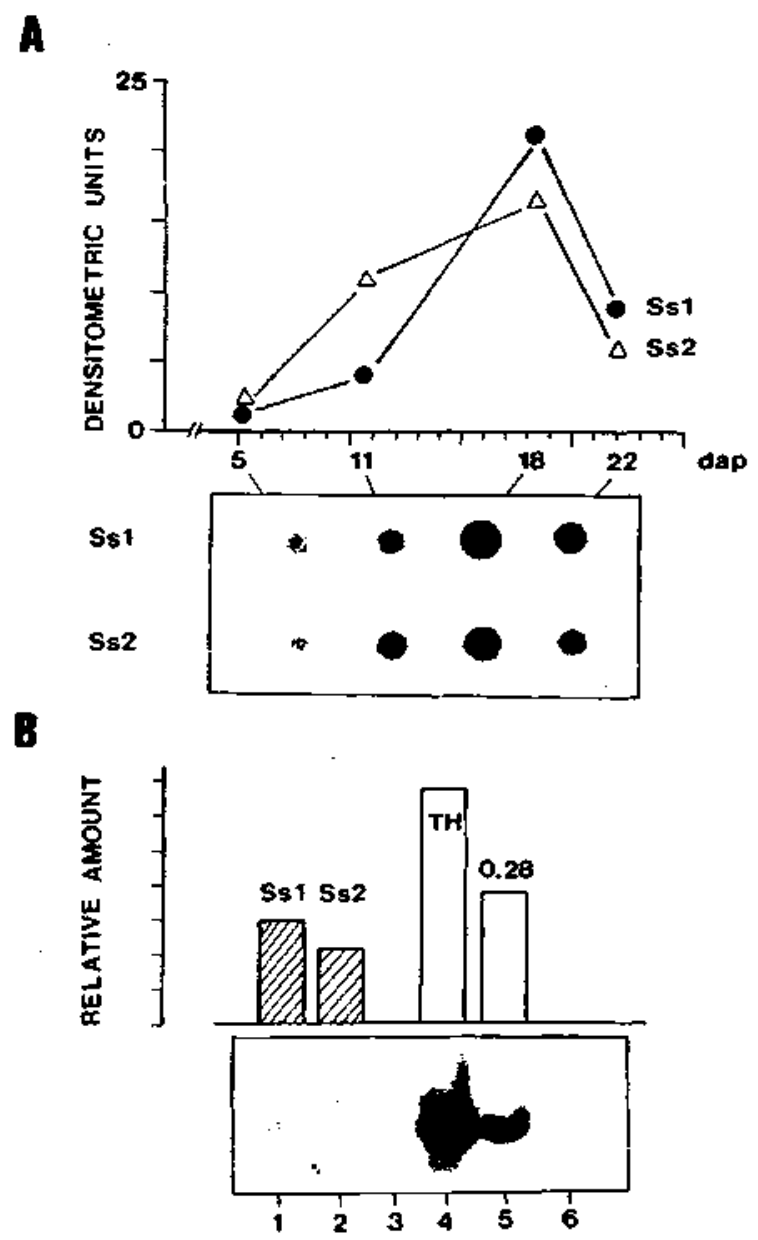

Fig. 2. Expression of $S s$ genes in wheat endosperm. (Panel A) Dot-blot hybridization of RNA from developing wheat endosperm collected at different dap, using the type-specific probes described in Fig. 1. The probes were ${ }^{32} \mathrm{P}$-labelled using the random primed DNA labelling kit of Boehringer (Feinberg and Vogelstein, 1983). Aliquots of denatured RNA (from $0.4 \mu \mathrm{g}$ to $10 \mu \mathrm{g}$ ) were applied to nitrocellulose membranes (Hybond C, Amersham), using a Hybri-dot ${ }^{\text {TM }}$ manifold, and the wells were rinsed with $15 \times$ SSC (White and Bancroft, 1982; Maniatis et al., 1982). (Panel B) Hybridization of Southern-blotted cDNAs with ${ }^{32}$ P-labelled RNA from 20 dap developing endosperm. (1) Type-specific $S s /$ probe; (2) typespecific Ss2 probe; $(3,6)$ p\#R322; (4) $\times 2$-thionin cDNA clone; (5) $\alpha$-amylase inhibitor $(0.28)$ clone. In this and subsequent figures, the Southern-blotted probes were hybridized with radioactively-labelled RNA obtained from 20 dap endosperm. As expected, the level of the $S s I$ type was about $20 \%$ higher than that of the $S s 2$ type, and both were expressed at a lower degree than mRNAs of fairly abundant endosperm proteins, such as $\alpha$-thionin and the $0.28 \alpha$-amylase inhibitor (Fig. 2B). Changes of $S s l$ and $S s 2$ mRNA levels during endosperm development are in line with previous measurements of the overall sucrose-synthase enzymatic activity at different limes after pollination (Chevalier and Lingle, 1983; Dale and Housley, 1986). The $S s 2$ type predominates in the early stages and then the $S$ sl type increases rapidly to become dominant. In maize, where the proteins from the $S h$ and $S u s$ genes have been separated from each other (Chourey et al., 1986), a greater dominance of the first protein has been observed as early as 12 dap. The smaller excess of $S s l$ over the $S s z$ mRNA in wheat endosperm, in comparison with maize, might simply reflect the different size and geometry of the wheat kernel.

In contrast with the endosperm situation, the $S s I$ type is several times more abundant than the $S s 2$ type in etiolated leaves and in roots from seven day plants, and the overall sucrose-synthase messenger levels are considerably lower in these organs than in endosperm (Fig. 3), as is the case in maize. densitometric quantitation of hybridization signals was carried out directly in the autoradiograph. In the case represented in panel B hybridization bands were excised and counted, and a correction for the differences in insert size has been introduced: for $S s I, 955 / 250$ (bp TH/bp $S_{s} /$ ); for $S s 2,95 s / 270$ (bp TH/bp $S s 2$ ); for $0.28,955 / 689$ (bp TH/bp 0.28). The cDNAs were subjected to electrophoresis in $1.5 \%$ agarose gels. Partially hydrolyzed total RNA $(1 \mu \mathrm{g})$ was labelled with $30 \mu \mathrm{Ci}$ of $\left[\gamma^{-32} \mathbf{P}\right] \mathrm{ATP}$ and used to hybridize the Southern-blotted plasmids as described by Bedbrook el al. (1980). The membranes used were processed according to the manufacturer's instructions, and exposed to MAFE $R P-X 7$ films at $-70^{\circ} \mathrm{C}$ with intensifying screens. 
A

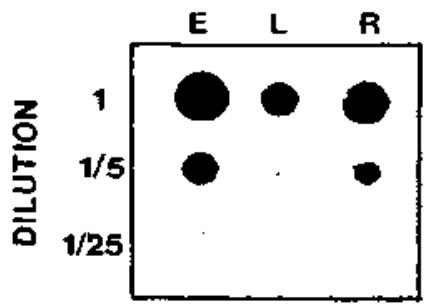

Ss1

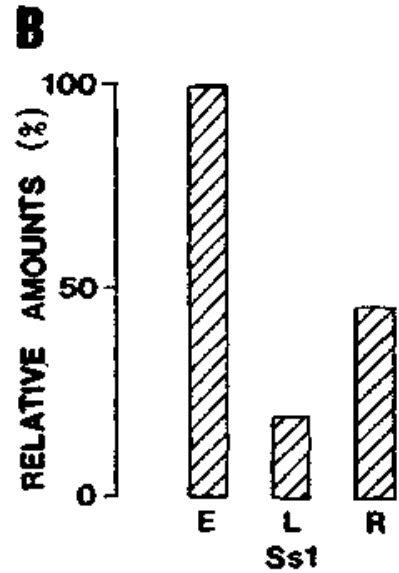

A

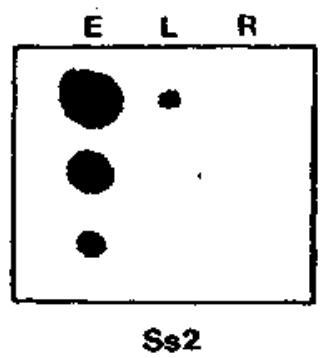

S\$2

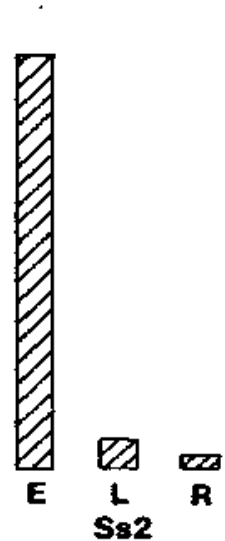

Fig. 3. Tissue-specificity of $S s$ genes. (Panel A) Dot-blot bybridization of RNA from 20 dap endosperm (E), 7d roots (R) and seven day etiolated leaves (L) with the type-specific $S_{s} /$ and $S s 2$ probes. Dilution 1 corresponds to $10 \mu \mathrm{g}$ of total RNA. (Panel B) Densitometric quantitation referred to the endosperm value $(100 \%)$ obtained with each of the probes. Experimental details as in Fig. $2 \mathrm{~A}$.

(c) Differential expression of $S s 1$ and $S s 2$ genes in response to anaerobiosis, cold shock and light

Responses of the two types of genes to environmental stimuli were investigated using the type-specific probes. The effect of anaerobiosis was studied both in a confined atmosphere and by immersion in buffer with practically the same results. The level of $S s I$ messengers increased fivefold while that of the $S_{S} 2$ type remained essentially unchanged both in etiolated leaves and in roots (Fig. 4). A similar effect was observed in response to cold shock. When plants were exposed to $6^{\circ} \mathrm{C}$, higher levels of $S s I$ messengers were detected, especially in roots, with no significant changes in those of the Ss2 type (Fig. 4). Exposure to ethylene did not alter the levels of either type of messenger (Fig. 4). The differential response of the $S s I$ and $S s 2$ types of wheat genes to anaerobiosis was consistent with their proposed equivalence to the maize $S h$ and $S u s$ genes, respectively (Marana et al., 1988a,b) although the response of the $S h$ gene was more drastic (McCarty et al., 1986; Springer et al., 1986) than that of the SsI gene, and the Sus gene did have some response (McCarty et al., 1986) while the wheat $S s 2$ was little affected.
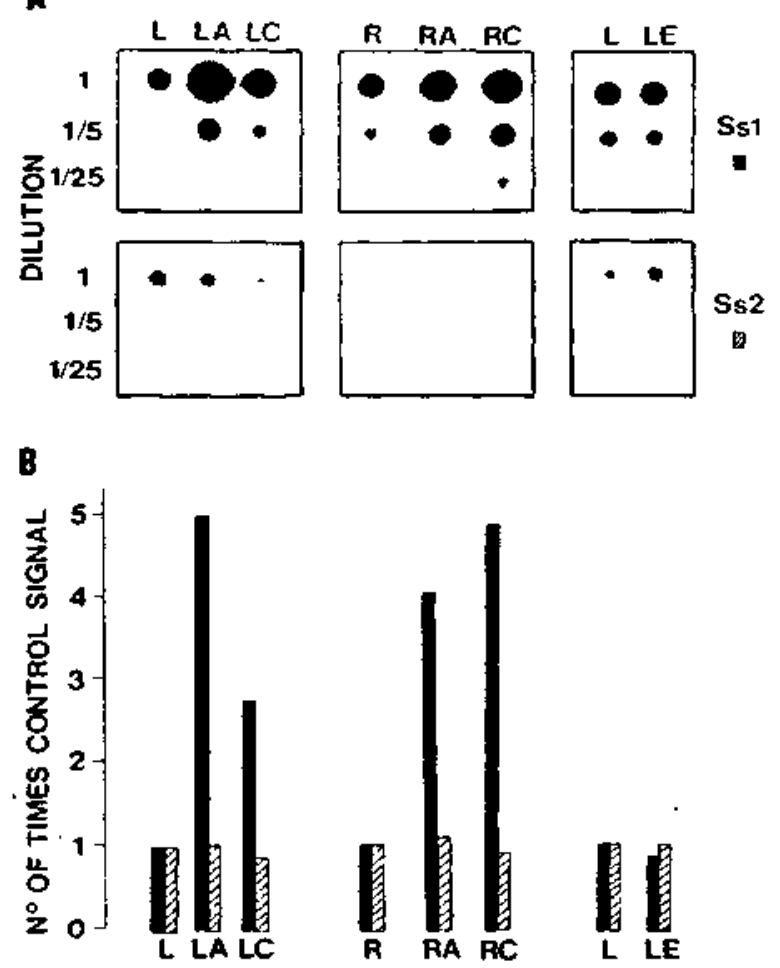

Fig. 4. Response of $S s l$ and $S s 2$ genes to anaerobiosis, cold shock and ethylene treatment. (Panel A) Dot-blot hybridization of RNA from darkgrowt plants exposed to anaerobiosis, to cold $\left(6^{\circ} \mathrm{C}\right)$, and to ethylene as described in MATERIALS AND METHODS, section (a); etiolated leaves ( $L$ ) and roots ( $R$ ) from control plants; the same organs from plants subjected to anaerobiosis (LA, RA), cold (LC, RC) and leaves after ethylene treatment (LE). Dilution 1 corresponds to $10 \mu \mathrm{g}$ of total RNA. (Panel B) Densitometric quantitation referred to the signal intensities of control plants with probes specific for Ssl (solid bars) and $S s 2$ (hatched bars). Experimental details as in Fig. $2 \mathrm{~A}$.

Cold shock differentially affected the expression of the two types of wheat genes in much the same way as anaerobiosis although, in this case, induction seemed to be stronger in roots than in leaves. This observation, which has not been previously reported for the maize genes, indicates that the $S S I$ genes are responsible for the previously observed increase in sucrose-synthase enzymatic activity, which starts within one hour after wheat plants have been exposed to cold shock and proceeds over several days, while all other enzymes related to sucrose biosynthesis do not modify their activities (Calderon and Pontis, 1985).

Ethylene application has been found to affect sucrose distribution within carnation flowers (Nichols and Ho, 1975 ) and ethylene production increases rapidly following trauma caused by different agents, including temperature extremes (Unsworth, 1987). Ethylene application did not affect either $S s 1$ or $S s 2$ mRNA levels, indicating that the observed induction of the $S s I$ genes in response to anaerobiosis and to cold stress is not mediated by ethylene. 


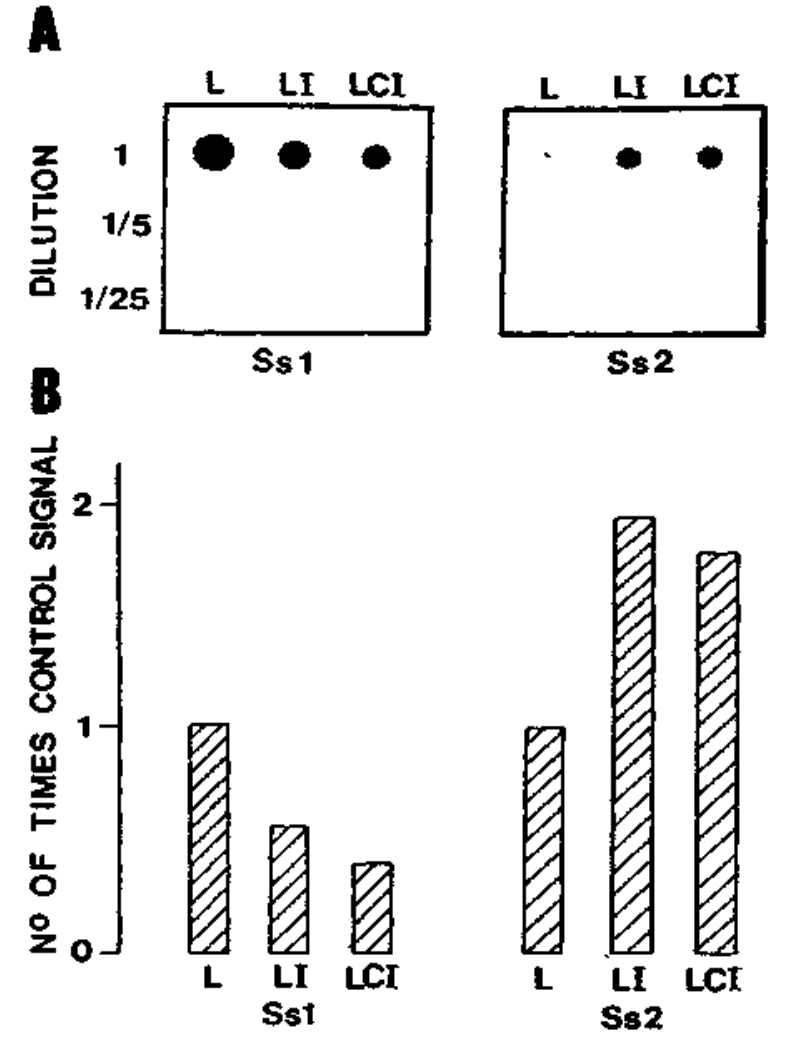

Fig. 5. Response of $S$ s genes to light. (Panel A) Dot-blot hybridization of RNA from plants exposed to light: (L) leaves from nine-day-old darkgrown plants; (LJ) leaves from plants grown in the dark for seven days and continuously illuminated for $48 \mathrm{~h}$; (LCI) leaves from plants grown under continuous illumination for nine days. Dilution 1 corresponds to $10 \mu \mathrm{g}$ of total RNA. (Panel B) Densitometric quantitation of signals in panel A. An arbitrary value of 1 was given in each case to the signal corresponding to leaves from dark-grown plants (L). Experimental details as in Fig. 2 A.

Upon illumination, a differential response was also obtained but in the opposite direction as that just described: while $S S I$ messengers decreased, especially under prolonged illumination, the $S s 2$ messengers underwent a consistent increase (Fig. 5). A decrease of the Sh messenger upon illumination has been reported for maize leaves (Springer et al., 1986), while the effect of light on the Sus gene has not been investigated.

The two types of wheat sucrose synthase genes, $S_{S} l$ and $S s 2$, correspond to the $S h$ and $S u s$ genes of maize, not only on the basis of their coding nt sequences, as previously proposed by us, but also in regulatory terms. The basic regulatory differentiation of the two types of genes must have occurred after intrachromosomal duplication, prior to the evolutionary branching-out between maize and the diploid species that formed the hexaploid wheat. It is of interest to point out that, as suggested by us (Maraña et al., 1988a,b), other genes located in chromosome 9 of maize, such as Bronze and Waxy, have their corresponding homologous sequences in group 7 chromosomes of wheat (Chao et al., 1988).

\section{(d) Conclusions}

(1) The two types of sucrose-synthase genes, SsI and $S s 2$, are differentially expressed in different wheat tissues and in response to environmental stimuli, as judged by dot-blot hybridization of RNA with type-specific probes.

(2) Both genes types are highly expressed in endosperm, whereas expression of the $S s I$ type clearly predominates over that of the $S s 2$ type in leaves and roots.

(3) Anaerobiosis markedly increases steady-state levels of $S s] \mathrm{mRNA}$ in roots and leaves, while those stimuli do not affect the levels of the $S s 2$ mRNA. This is in line with the previously proposed correspondence of $S s]$ and $S s 2$ gene types from wheat with the $S h$ and $S u s$ genes from maize.

(4) $S_{s} /$ genes respond to cold shock $\left(6^{\circ} \mathrm{C}\right)$ by increasing their steady state mRNA levels, an effect which has not been reported for the maize genes.

(S) Light decreases expression of the $S s I$ genes and increases that of $S s 2$ genes.

\section{ACKNOWLEDGEMENTS}

The technical assistance of L. Lamoneda, C. Rojas and J. García is gratefully acknowledged. C. Marafia was the recipient of a postdoctoral contract from Centro Nacional de Biotecnologia. This work was financially supported by Comisión Asesora de Investigación Cientifica y Técnica (grant PB85-0193).

\section{REFERENCES}

Bedbrook, J.R., Smith, S.M. and Ellis R.J.: Molecular cloning and sequencing of cDNA encoding the precursor to the small subunit of chloroplast ribulose-1,5-biphosphate carboxylase. Nature 287 (1980) 692-697.

Burr, B. and Burr, F.A.: Controlling-element events at the shrunken locus in maize. Genetics 98 (1981) 143-156.

Calderon, $P$. and Pontis, H.G. lncrease of sucrose synthase activity in wheat plants after a chilling shock. Plant Sci. 42 (1985) 173-176.

Cardini, C.E., Leloir, L.F. and Chiriboga, J.: The biosynthesis of sucrose. J. Biol. Chem. 214 (1955) 149-155.

Chao, S., Sharp, P.J. and Gale, M.D.: A linkage map of wheat homologous group 7 chromosomes using RFLP markers. In Miller, T.E. and Koebner, R.M.D. (Eds.), Proc. 7th Int. Wheat Genet. Symp. Inst. Plant Sci. Res., Cambridge, 1988, pp. 493-498.

Chevallier, P. and Lingle, S.E.: Sugar metabolism in developing kernets of wheat and barley. Crop. Sci. 23 (1983) 272-277.

Chourey, P.S.: Genetic control of sucrose symthetase in maize endosperm. Mol. Gen. Genet. 184 (1981) 372-376.

Chourey, P.S. and Nelson, O.E.: The enzymatic deficjency conditioned by the shrunken-1 mutation in maize. Biochem. Genet. 14 (1976) $104 \mathrm{I}-1055$. 
Chourey, P.S., Latham, M.D. and Stilt, P.E.: Expression of two sucrose synthetase genes in endosperm and seedlings of maize: evidence of tissue specific polymerization of protomers. Mol. Gen. Genet. 203 (1986) 251-255.

Dale, E.M. and Housley, T.L.: Sucrose syuthase activity in developing wheat endosperm differing in maximum weight. Plant Physiol. 82 (1986) 7-10.

Echt, C.S. and Chourey, P.S.: A comparison of two sucrose synthetase isozymes from normal and shruken-1 maize. Plant Physiol. 79 (1985) $530-536$.

Feinberg, A.P. and Vogejstein, B.: A technique for radiolabeling DNA restriction endonuclease fragments to high specific activity. Anal. Biochem. 132 (1983) 6-13.

Larsen, A.E., Salerno, G.L. and Pontis, H.G.: Sucrose synthase from wheat leaves. Comparison with the wheat germ enzyme. Physiol. Plant 67 (1985) 37-42.

Logeman, J., Schell, J. and Wilmitzer, L.: Improved method for the isolation of RNA from plant tissues. Anal. Biochem. 163 (1987) $16-20$.

Maniatis, T., Fritsch, E.F. and Sambrook, J.: Molecular Cloning. A Laboratory Manual. Cold Spring Harbor Laboratory, Cold Spring Harbor, NY, 1982.

Maraña, C., Garcia-Olmedo, F, and Carbonero. P.: Linked sucrose synthase genes in group-7 chromosomes in hexaploid wheat (Triticum aestivum L.). Gene 63 (1988a) 253-260.

Maraña, C., García-Olmedo, F. and Carbonero, P.: Equivalent locations of sucrose synthase genes in chromosomes $7 \mathrm{D}$ of wheal, $7 \mathrm{Ag}$ of Agropyron elongatum, and 7H of barles: FEBS Lett. 234 (1988b) 417-420.

McCarty, D.R., Shaw, J.R. and Hannah. L.C.: The cloning, genetic mapping, and expression of the constitutive sucrose synthase locus of maize. Proc. Nat3. Acad. Sci. USA 83 (1986) 9099-9103.

Nichols, R. and Ho, L.C.: An effect of ethylene on the distribution of $\left[{ }^{14} \mathrm{C}\right]$ sucrose from the petals to other flower pars in the senescent cut inflorescence of Dionthus caryoph!liks. Ann. Bot. 399 (1975) 433-438.

Ponz, F., Paz-Ares, J., Hernandez-Lucas, C., Garcia-Olmedo, F. and Carbonero, P.: Cloning and nucleatide sequence of a cDNA encoding the precursor of the barley toxin $\alpha$-hordothionin. Eur. J. Biochem. 156 (1986) 13]-135.

Springer, B., Werr, W., Starlinger, P., Bennett, D.C., Zokolica, M. and Freeling, M.: The shrunken gene on chromosome 9 of $Z$ eo mays $L$. is expressed in various plant tissues and encodes an anaerobic protein. Mol. Gen. Genet. 205 (1986) 461-468.

Su, J.C. and Preiss, J.: Purification and properties of sucrose synthase from maize kernels. Plant Physiol. 61 (1978) 389-393.

Unsworth, M.: Adding ethylene to injury. Nature 327 (1987) 364-365.

Werr, W., Frommer, W.B., Maas, C. and Starlinger, P.: Structure of the sucrose synthase gene on chromosome 9 of Zea mays L. EMBO J. 4 (1985) 1373-1380.

White, B.A. and Bancroft, F.C.: Cytoplasmic dot hybridization: simple analysis of relative mRNA levels in multiple small cell or tissue samples. J. Biol. Chem. 257 (1982) 8569-8572. 